\title{
GOING GREEN IN CONSUMPTION: A MARKETING STRATEGY DEVELOPMENT STUDY
}

\author{
Dr. Senthil Nathan $C^{*}$ \\ Assistant Professor- Senior Grade, Marketing Area, SRM-College of Management, SRM- \\ Faculty of Management, SRM Institute of Science and Technology, \\ Chennai, Tamil Nadu, India \\ Dr. Premlatha S \\ Professor, Marketing Area, SRM-College of Management, SRM-Faculty of Management, \\ SRM Institute of Science and Technology, Chennai, Tamil Nadu, India

\section{Dr. K. Sadasivan} \\ Professor, SRM-College of Management, SRM-Faculty of Management, SRM Institute of \\ Science and Technology, Chennai, Tamil Nadu, India \\ *Corresponding Author
}

\begin{abstract}
Eco-consciousness and importance for personal health and well-being among consumers have led to a marketing opportunity for green products in the dynamic marketing environment. Marketing of products with less detrimental impact on environment will come under natural marketing environment factor in marketing environment. This environment will have greater influence in marketing of products and services in future because of increased environmental pollution. To utilise opportunities and enhance the consumption of natural products, developing a marketing strategy is imperative. This study had attempted a marketing strategy for consumption of green products by non-buyers of existing green products in market. It is imperative to understand nonbuyers' buying intention when adopting the marketing strategy and expectations regarding product, price, and promotion. The study results shows Nonbuyers had positive response for marketing strategy attempted by this study in the four product categories studied and thrown light regarding their expectations in product, price, place and promotion. The findings of this study can help in developing marketing strategies and refining the marketing mix for preventing climate change effects and environmental pollution. The study results can be used as base for further research in different global markets to facilitate green consumption and reduce environmental pollution.
\end{abstract}


Key words: Marketing Strategy, Green variant, Green Marketing, Line Extension strategy, Brand Extension strategy, Environment.

Cite this Article: Senthil Nathan C, Premlatha S and K. Sadasivan, Going Green in Consumption: A Marketing Strategy Development Study, International Journal of Management (IJM), 11(12), 2020, pp. 3085-3103.

http://iaeme.com/Home/issue/IJM?Volume=11\&Issue $=12$

\section{INTRODUCTION}

In the current scenario, among various marketing environmental factors, the natural marketing environment exerts a significant effect. The global climate risk index published in 2019 and 2020 by an environmental think tank in Germany indicated that countries such as Japan, Germany, the United Kingdom, and the Philippines were the most affected by climate change in the last two years, resulting in loss of lives and hospitalisation of people. The economic impact of climate change is higher in developing nations than in developed nations. India has experienced water shortages, crop failures, and worst flooding in the last two years. In summer, heat is extremely intensive, and the summer season occurs for approximately 8 months a year in certain states of India, leading to water shortage. This results in crop loss in the agricultural sector, affecting the economy of the country. Furthermore, this leads to financial loss to governments because of the loss of productivity owing to the effects of climate change on infrastructure and the lives and health of humans. In many parts of India, the average summer temperature has increased by $2^{\circ} \mathrm{C}$ from $40^{\circ} \mathrm{C}$ to $42^{\circ} \mathrm{C}$ in the last 10 years. Globally, countries such as France, Germany, and the United Kingdom have experienced very high temperatures never seen before. From the beginning of the 21 st century, glaciers that are melting provide more fresh water than required, eventually resulting in the provision of little fresh water for billions of people who depend on it. The ways in which goods are produced and consumed need to be changed to prevent the adverse effects of global warming, climate change, and environmental pollution. This indicates that the present marketing environment is significantly affected by the natural marketing environment. According to a New York Times article published in March 2020, the increased air pollution levels will be conducive for the contraction and contagiousness of pandemic diseases such as the coronavirus.

\section{Marketing with social responsibility for consumer well-being}

Marketing involves all methods and processes developed to create and facilitate the exchange of goods and services intended to satisfy the needs and wants of humans. Currently, it is crucial to identify the needs and wants and accordingly create products with value; it is important to deliver products with a higher value than those of products offered by competitors in the market.

According to Ottman and Davis (1998) and Kangun (1994), green marketing involves all activities designed to develop and facilitate any exchanges intended to satisfy the needs and wants of humans, such that the satisfaction of these needs and wants will happen with very less detrimental impact on the environment that is to be preserved for society well-being. Natural marketing environment factor in marketing environment factors focus on environmental pollution, it's impact on society and government regulation for manging it in manufacturing and marketing. It will have wide influence in any market in future. Marketers should rethink and develop marketing strategies so that the market share can be sustained and increased as well as utilise marketing opportunities owing to the effect of natural marketing environmental factors. Going green in consumption by consumers and developing marketing strategies for enhancing the consumption of green natural products can enhance green product consumption and contribute to social well-being, thus reducing environmental pollution and its adverse effects. 
The aim of this study is to develop marketing strategies to modify the behaviour of nonbuyers who did not buy existing green products available in the market. This study attempts to develop marketing strategies to convert nonbuyers who do not buying existing green products into buyers. The findings of this study can aid marketers in enhancing green consumption by utilising opportunities provided by natural marketing environmental factors. Increased green consumption can be beneficial for the future and result in social well-being, thus moderating the adverse effects of climate change, global warming, and environmental pollution.

\section{LITERATURE REVIEW}

Horne (2009) found that recent climate changes have attracted the interest of green and modern green buyers to search for and then demand for green products. The most common questions surrounding green marketing is what creates interest among consumers and what gets them to act on these interests. Essoussi and Linton (2010) indicated that consumers have in-depth concerns for environmental pollution and express them; however, the attitude of these consumers is not felt in consumption practices, and the attitude formed is yet to be studied explicitly. The major barrier for consumers in buying green products is their worry of not having the provision to test the capability and performance of the product before buying it.

Marketers should adopt green marketing in such a way that they should take the advantage of market opportunities arising from green consumption and should also know regarding the threats of green changes happening in the market in order to neutralise threats and turn them into opportunities. McCarty et al (1995) have reported that consumers taking special efforts to purchase green products will not engage in impulse (spot) buying and show brand loyalty. Duber-Smith (2002) indicated that the marketing of natural products is emerging over a period of time. For their personal health and environment well-being, consumers demand products that are free from chemical impurities and biodegradable. In terms of buying green products, consumers' age, gender, and education are not important, but psychological factors, such as their attitude and belief, play a crucial role. These findings indicate that the consumer demand for natural products is increasing because of the effects of climate change; however, it is imperative to understand consumers in order to take the advantage of opportunities.

Green consumerism is still a considerably limited phenomenon regarding both the share of green consumers in the overall population and the willingness to pay for environmentally superior products even among those concerned about the environment. On the basis of a study conducted in the Indian market, Jain and Kaur (2004) reported that companies should understand the real concern among consumers and incorporate eco-friendly manufacturing and marketing practices; otherwise, they would have to face severe opposition from the consumer fraternity in the near future because of the increasing green sentiments of consumers, as determined in their extended research conducted in 2006. Formichelli (2007) found that organic buyers are a minority when compared with what is available and what people are buying, even among those who are highly environmentally oriented; one in four consumers will buy products many times in a week .Organic buyers are willing to buy products in the categories of natural household cleaning, eco-tourism, organic pet care, and personal care. Bhatia (2013) reported that consumers are concerned regarding the environment and the innovation of green produce should exceed over conventional products because the buying and consumption of green products are low; the market should keep exploring opportunities and formulating promotional methods.

The existence of an adequate number of consumers who are willing to pay a premium for environmentally friendly products is enough to warrant the attention of marketers. However, there is also a large segment of undecided consumers who may be persuaded to move into the 'willing to buy' segment through the adoption of suitable marketing mix strategies (Valor, 
2008). Durmaz and Zengin (2011) indicated that the right target segment should be identified and its needs should be mapped through relevant (4 Ps product, price, place and promotion) marketing strategies. This will give rise to an opportunity for green marketing with continuous growth in the long term and profitability for the marketers of green products. Furthermore, this growth and profitability will help in entering new markets where the company will have an advantage over competitors (Godelnik, 2012; National Geographic Greendex, 2012). Consumers are ready for green consumerism, and government should play a pivotal role in the growth of green products. Holistic green marketing should be the focus of all stakeholders to enable green marketing. Green manufacturer's reputation plays an important role. Rao (2014) indicated that it will not be easy for all companies to adopt green marketing. These findings imply that there is an opportunity for marketing natural products, but a strategy and appropriate marketing mix must be developed for attracting the majority of consumers to purchase green products. To develop an appropriate marketing strategy and implementing the same, it is imperative to understand consumer expectations.

Johrilalit and Sahasakmontri (1998) reported that a company should offer high-quality natural products prepared using natural ingredients with the minimum use of chemicals that exert harmful effects on humans. Consumers will be attracted to buy green products based on their high quality, ability to save water and reduce power bills, portability, and presence of nontoxic ingredients that are safe for children. (Ottman, 1998). Gupta (2008) indicated that green products are those that require less energy and water; those that are naturally processed, release less energy, and are less perilous; and those which do not emit toxic substances, eliminate pesticide treatment, reduce water pollution, save and conserve energy, contribute to a healthy environment, reduce indoor contaminations, and also prevent noise. Peart (2010) found that a consumer payment for a product depends not only on its green attribute but also the value addition of the product in terms of taste, safety, or low price that can help buyers of the product save money. Brand image and reputation are concerns in green-buying decisions. Consumers have an inclination towards green products, but the ability of consumers to pay for green products remains unknown. Bahnan et al (2011) found that for young consumers, ease and access are important in green consumerism. Older consumers consider reducing environmental damage by consuming green products. According to older consumers, green marketing can reduce environmental damage. Green innovation represents the concept of integrating environmental protection into the design of products. Green promotion refers to the communication that promotes the product and services. In addition to promoting the green advertising campaign, green promotion should also enhance the corporate image of social responsibility. Thus, the success of green innovation and green promotion affects firms' performance (Hasanaetal, 2015).

Kuhn (2005) reported that if the consumption of an environmentally friendly product generates an extra benefit in the form of subsidiary, then there exists a private incentive to engage in green consumerism and the social dilemma is overcome. Peattie and Crane (2006) indicated that green products are expected to have superiority over conventional products in terms of being environmentally friendly, and simultaneously, they should add value in terms of the price paid. In the real market, the marketing of green products is characterised by uneven competition in the market because of the environmental subsidy in society that many normal products enjoy and the performance effects of regular non-green products in removing harmful product ingredients. Ottman (1998) reported that a company should consider environmental aspects while integrating with all marketing aspects. For example, in new product development, communication with consumers and all points between environmental issues and green marketing should be balanced with the basic needs of customers. Chen (2008) found that the number of green customers is high, and marketers are attempting to respond to the developments of the external environment to enhance their activities in terms of preserving the 
environment. Consumers trust popular brands among green products and judge the performance of eco-friendly products based on the previous purchase and usage experience of the products and referral word of mouth regarding the products. Consumers often have difficulty in identifying green products; thus, as an effective marketing strategy, information regarding the benefits of products and product improvements, such as a new improved formula, should be conveyed to consumers. (Pickett-Baker and Ozaki, 2008). Lee and Hooper (2016) found that there is a marginal improvement in consuming differently because of the socio-cultural environment. Thus, whether these marginal improvements will make a difference to society or whether they will collectively improve the environment remains unclear. Thus, the expectations of consumers regarding an eco-friendly, green, or natural product and its promotion and price differ among different categories of segments. Although the literature provides broad insights into consumer expectations regarding natural products, studies focusing on a particular product category are limited, and the buying behaviour varies according to sociocultural and economic factors. Majhi(2020) in their academic paper stated young generation possess higher level of knowledge and awareness regarding environmental pollution and it's adverse effects which drives them to go green in consumption. Aich (2006) reported that the difficulty was in bringing organic products and promoting these products considering the fact that the other mainstream category of products was not in the green category. If personal product players, such as Unilever and $P \& G$, develop natural products, they should bring it to notice that it was an evolutionary process to transcend their journey to organic products; hence, the existing brands were not organic. Nargundar (2016) reported that consumers based in India give importance to packaging, followed by eco-certification and lifestyle. In metro cities, although people are conscious regarding health and the environment, purchase is not occurring at the same phase. In growing economies such as India, green marketing should consider the economic aspect of marketing. Lakshmi and George(2018) in their research work highlighted the importance of role of government policies and industry's social responsibility for going green because of increased knowledge of consumers about environment. Although green products are available in the market, there are nonbuyers who do not buy these products because of various factors such as not trusting the green products available in the market and loyalty to the regular nongreen brand they usually buy. These results indicate that a marketing strategy should be developed so that regular non-green brand manufacturers that are well-known in the market can enhance green consumption by converting nonbuyers into buyers. Creating a favourable attitude towards health, wellness, and environmental sensitivity is key for the success of natural brands. Newman (2006) and Guzman (2008) found that natural cosmetics, which appear to be a niche segment, has recently moved to the main stream market. Regulations should be strict for natural personal care players; otherwise, non-natural players will easily position themselves as natural players. Formulation of cosmetics containing pure natural ingredients is difficult without the use of synthetic and semi-synthetic ingredients. Currently, regulations for natural personal care products are not full-fledged. Thus, there is a need for studies to find market opportunities if green or natural personal care products are introduced as green variants by wellknown brands in the personal care segment because of the trust they have from their loyal customers.

To sum up, the effect of climate change and pollution and consumers' positive attitude towards health and well-being have provided a market opportunity for green or natural products that are manufactured and marketed with the minimum detrimental impact on the environment. To utilise the opportunities and enhance the consumption of natural products, an innovative marketing strategy is essential because there are many nonbuyers who do not buy green or natural products existing in the market. This study developed an innovative marketing strategy wherein a green variant was introduced as a line extension strategy by the regular manufacturers of non-green personal care products. We further determined the response of buyers because of 
consumers' trust well-known brands in the personal care segment. To determine the success of this strategy, we attempted to understand nonbuyers' intention to purchase the green variant when introduced by their regular non-green brand manufacturer and their expectations regarding the product and its price and promotion.

Although research had been conducted in areas of market opportunities for green products, there is a research gap in terms of expectations for a particular product category if a green variant is introduced by mainstream manufacturers for successful sales. There is positive inclination towards green products, personal health, and well-being among consumers. This study narrowed down product-category-wise research on the personal care product category and implemented a new marketing strategy to enhance the consumption of natural products among nonbuyers and the scope for green marketing adaptation, facilitating sustainable consumption.

\section{Research Objectives of the Study}

- To determine the buying intention of green or eco-friendly products by nonbuyers when the line extension strategy is adopted by existing regular non-green personal care product manufacturers through the introduction of eco-friendly varieties.

- To identify the expectations of nonbuyers who have a positive buying inclination when the regular non-green brand manufacturer they regularly purchase introduces an ecofriendly variety in the personal care product category.

\section{METHODOLOGY}

\subsection{Green Variant and Sustainable Consumption}

A 'green variant' is defined as a product with less chemicals (less than $0.1 \%$ of the ingredients used in production). The term 'green variant' mentioned in this study refers to environmentally friendly alternatives introduced by regular brand manufacturers (such as Unilever), which is a line extension strategy of the existing brands of personal care by the mainstream manufacturer. These eco-friendly variants are manufactured using eco-friendly ingredients by adopting sustainable production methods, consuming less water, power, and resources, thus resulting in less environmental pollution. The formulation of an efficient marketing strategy to enable the consumption of these products can help in going green in consumption.

\subsection{Green Product/Natural Product}

The terms 'green product', 'natural product', and 'eco-friendly product' used in this study indicate a product with less chemicals compared with those used in regular products. These products are manufactured and marketed with the minimum detrimental impact on the environment. The consumption of these products leads to sustainable consumption.

\subsection{Method and Procedure}

This descriptive research study involved the use of focused and formulated research questions. The survey was conducted on a large group of respondents in two different cities.

\subsection{Sampling Method}

Purposive sampling was adopted in the study, and two cities in India were included. Cities that have a high number of eco-friendly product retail shops were selected for inclusion. Primary data were collected using a structured questionnaire and through interviews. 
Purposive sampling is also known as judgement sampling. By using the sampling method, nonbuyers of eco-friendly products were identified as those who do not buy a single ecofriendly product despite the presence of retail shops selling green products in their vicinity.

The retailers of green products were first identified. To identify buyers and nonbuyers of the retailer, a pilot study was undertaken by including 100 residents of a city. After the identification of retailers their customers located within a $10-\mathrm{km}$ radius of retail shop were interviewed on customer locations. This enabled us to identify the buyers and nonbuyers of green products. The pilot study experience was used in actual research survey of respondents for accuracy in results. The purposive sampling method had been adopted for fulling the objective of the study.

\subsection{Questionnaire Construction}

We reviewed the findings of studies from various countries published between 1991 and 2016. Furthermore, we considered the market environment where the study was conducted and accordingly prepared the questionnaire. After completion of questionnaire construction, a pilot study was conducted by including 100 respondents, and the questionnaire was refined further to ensure the validity and reliability of scales used in it. Thus, the accuracy of the questionnaire was determined by conducting a pilot study before the actual survey.

\subsection{Validity of the Research Instrument}

Content Validity: Green consumption is an emerging area in India, and the research instrument used was reviewed by a panel of experts who were retailers involved in buying and retailing green personal care products for nearly 5 years. After considering the review comments provided by these experts, questions in the questionnaire were fine tuned to ensure adequate coverage of research objectives.

\subsection{Reliability}

Cronbach's alpha was calculated to examine the reliability of the scale used in this study. The 5-point scale used in this study had a Cronbach' alpha value of $>0.6$.

\subsection{Multiple Regression Analysis for the Study}

The hypothesis was tested by performing multiple regression analysis. After formulating the scale by using factors determined in previous research conducted in this area, the scale was tested through a pilot study in the market where the research was conducted by considering the market environment. The final scale used in multiple regression was tested for validity and reliability to eliminate items that were not related. After examining the reliability and validity, the product expectation of nonbuyers was used as an independent variable in multiple regression to investigate its relationship with the green-buying behaviour of respondents, which was the dependent variable. Multiple regression analysis was performed for enhancing the accuracy of hypothesis testing.

\subsection{Hypothesis}

The study hypothesis was as follows: No significant relationship exists between nonbuyers' product expectation and buying preference of an eco-friendly variant when introduced by regular well-known brands used by the nonbuyers. 


\subsection{Proposed Model}

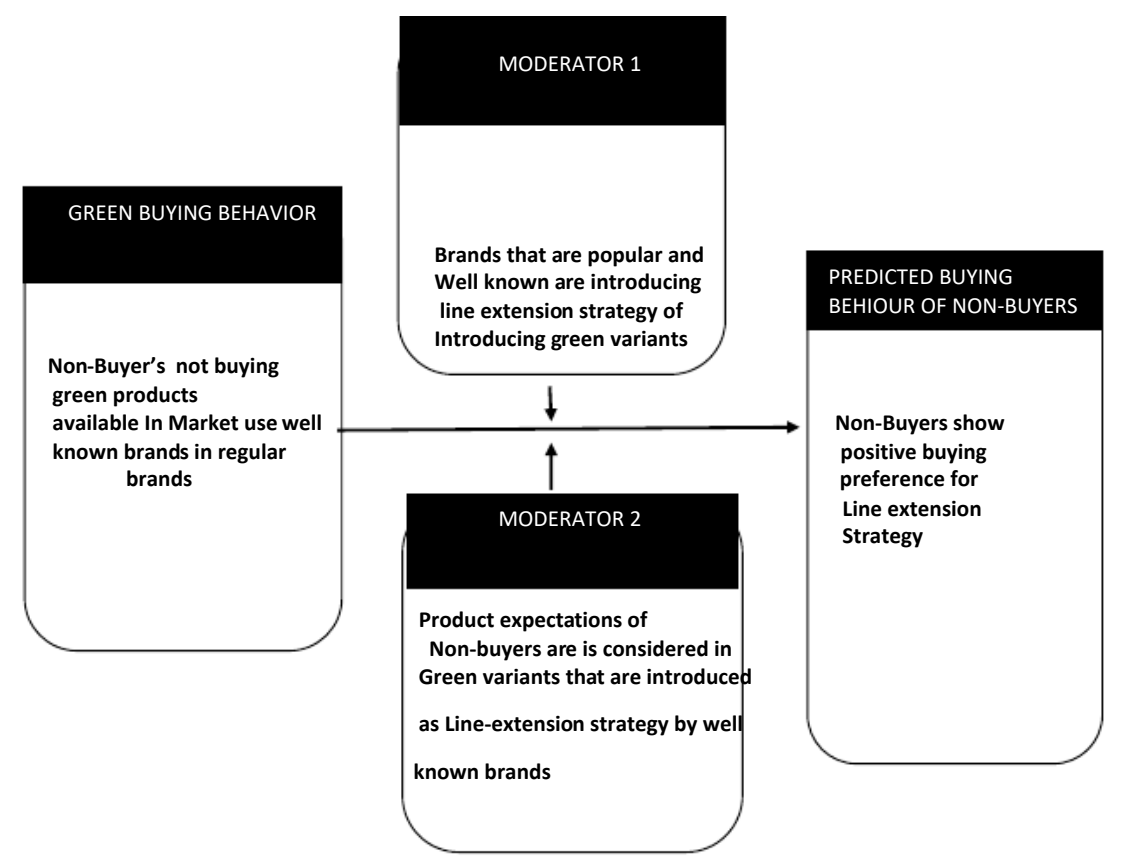

Figure 1

Table 1 Eco-Friendly Product categories used in the present research

\begin{tabular}{|l|l|}
\hline No. & Product category \\
\hline 1 & Personal care \\
\hline 2 & Bath soap \\
\hline 3 & Shampoo \\
\hline 4 & Tooth paste \\
\hline 5 & Face wash \\
\hline
\end{tabular}

Source: Author's own research

Sample: A total of 885 respondents were surveyed in both cities. The total number of the buyers and nonbuyers of eco-friendly personal care products was 484 and 401, respectively (Table 2).

The sample sizes surveyed in City 1 and City 2 were 445 and 440, respectively. The sample size represented the population adequately.

Table 2 Buyers/Nonbuyers in City 1 and City 2

\begin{tabular}{|c|c|c|c|c|c|c|}
\hline & \multicolumn{2}{|c|}{ CITY 1 } & \multicolumn{2}{c|}{ CITY 2 } & \multicolumn{2}{c|}{ Total } \\
\hline & Nos & Percentage & Nos & Percentage & Nos & Percentage \\
\hline Buyers & 180 & 40.4 & 304 & 69.1 & 484 & 55 \\
\hline Non-Buyers & 265 & 59.6 & 136 & 30.9 & 401 & 45 \\
\hline Total & 445 & 100 & 440 & 100 & 885 & 100 \\
\hline
\end{tabular}

Source: Author's own research.

Table 2 shows that City 1 had $59.6 \%$ of nonbuyers of eco-friendly products, and City 2 had $69.1 \%$ buyers. Overall, the percentage of the buyers of eco-friendly products was $55 \%$ and that of nonbuyers was $45 \%$. In locations where a less number of retailers were present, the proportion of nonbuyers will be higher. 


\section{RESULTS AND DISCUSSION}

Table 3 Demographic Details of Nonbuyers

\begin{tabular}{|c|c|c|}
\hline RESPONDENT AGE CATEGORY & Frequency & Percent \\
\hline $18-27$ & 92 & 23 \\
\hline $28-37$ & 124 & 31 \\
\hline $38-47$ & 139 & 35 \\
\hline $48-58$ & 46 & 12 \\
\hline Total & 401 & 100 \\
\hline $\begin{array}{l}\text { RESPONDENT'S GENDER } \\
\text { CLASSIFICATION }\end{array}$ & Frequency & Percent \\
\hline MALE GENDER & 211 & 53 \\
\hline FEMALE GENDER & 190 & 47 \\
\hline Total & 401 & 100 \\
\hline REPONDENT'S EDUCATION & Frequency & Percent \\
\hline HIGH SCHOOL LEVEL & 113 & 28 \\
\hline DIPLOMA LEVEL & 60 & 15 \\
\hline UNDER GRADUATE LEVEL & 158 & 39 \\
\hline POST GRADUATE LEVEL & 62 & 16 \\
\hline PHD LEVEL & 6 & 1.5 \\
\hline OTHERS & 2 & 0.5 \\
\hline Total Respondents & 401 & $100.0 \%$ \\
\hline INCOME CLASSIFICATION & Frequency & Percent \\
\hline Below INR 15000 & 84 & 21 \\
\hline BTEWEEN INR15000-25000 & 171 & 43 \\
\hline BETWEEN 25000-35000 & 67 & 17 \\
\hline BETWEEN INR 35000-45000 & 51 & 13 \\
\hline ABOVE INR 45000 & 28 & 7 \\
\hline Total & 401 & 100 \\
\hline FAMILY & Frequency & Percent \\
\hline NUCLEAR TYPE FAMILY & 298 & 74 \\
\hline JOINT FAMILY & 103 & 26 \\
\hline Total & 401 & $100.0 \%$ \\
\hline
\end{tabular}

Source: Author's own research

\section{Age Group of Nonbuyers}

The findings showed that the majority of nonbuyers belonged to the age group of 38-47 years (35\%), followed by the age groups of $28-37$ years (31\%), 18-27 years $(23 \%)$, and $48-58$ years $(12 \%)$. The majority of the nonbuyers of natural personal care products were men $(53 \%)$, with female buyers constituting only $47 \%$ of the sample. The majority of nonbuyers were undergraduate degree holders $(40 \%)$.

The majority of nonbuyers belonged to the income category of Rs. 15,001-25,000 (43\%). 
Table 4 Buying Preference of Green Variants by Respondents

\begin{tabular}{|l|r|r|r|r|r|}
\hline & Numbers & $\begin{array}{c}\text { Arithmetic } \\
\text { Mean }\end{array}$ & \multicolumn{1}{c|}{$\begin{array}{c}\text { Standard } \\
\text { Deviation }\end{array}$} & \multicolumn{1}{c|}{$\begin{array}{c}\text { Minimum } \\
\text { value }\end{array}$} & $\begin{array}{c}\text { Maximum } \\
\text { value }\end{array}$ \\
\hline $\begin{array}{l}\text { Buying preference of } \\
\text { tooth paste }\end{array}$ & 401 & 4.0848 & .81104 & 2.00 & 5.00 \\
\hline $\begin{array}{l}\text { Buying preference of } \\
\text { Bath Soap }\end{array}$ & 401 & 3.6858 & .73214 & 1.00 & 5.00 \\
\hline $\begin{array}{l}\text { Buying preference of } \\
\text { shampoo }\end{array}$ & 401 & 3.6284 & .73081 & 2.00 & 5.00 \\
\hline $\begin{array}{l}\text { Buying preference of } \\
\text { face wash }\end{array}$ & 401 & 3.5436 & .81775 & 1.00 & 5.00 \\
\hline
\end{tabular}

Source: Author's own research.

Table 4A Friedman Test for Ranking Difference in Buying Prefernce Among Proudct Categories

\begin{tabular}{|c|r|}
\hline Buying preference & $\begin{array}{c}\text { Mean } \\
\text { Rank }\end{array}$ \\
\hline Tooth paste & 2.89 \\
\hline Bath Soap & 2.45 \\
\hline Shampoo & 2.38 \\
\hline Face wash & 2.28 \\
\hline
\end{tabular}

Table 4B Friedman Test Results

\begin{tabular}{|l|r|}
\hline Numbers & 401 \\
\hline Value of Chi-Square & 160.801 \\
\hline Degree of freedom & 3 \\
\hline Assumed significance & .000 \\
\hline
\end{tabular}

Source: Author's own research.

As shown in Table 4, nonbuyers had a buying preference towards all personal care product categories when regular non-green brands manufacturer products used by them are launches a green variant. The arithmetic mean was above the average score of 3.0 for all product categories, indicating a highly positive buying preference among respondents.

As shown in Table 4B, the Friedman ranking test had a significance value of $<0.05$. This result indicates that there was a significant difference between the buying preference of different product types among the respondents if regular products used were introduced as a green variant. Table 4A shows that among different product types, toothpaste ranked the first (arithmetic mean: 2.89), followed by bath soap (2.45), shampoo (2.38), and face wash (2.28), in terms of buying preference when regular brands used are launched as green variants. These results indicate that among all product categories, toothpaste ranked the first for positive buying intention.

The product expectations studied for the four product categories are listed below with codes.

Table 5 Nonbuyers' Product Expecations Regarding Eco-Friendly Variants

(A1)-It must be environment-friendly, preserving earth and conserving water

(A2)- It must yield higher performance results when compared to regular non- green brand

-(A3)It must provide personal health care and well-being at higher level than regular brand(with chemicals).

-(A4). The packaging must be in environment friendly way that is bio-degradable and offering incentives for recycling of package 
-(A5) The price fixed for environment friendly products can be high and do not offer value for money paid(A5).

-(A6)- Promotion of products using brand ambassadors (Celebrities)

-(A7)-The store display on how buying of green brands are solutions to save planet earth.

-(A8)-Information to understand the extent of reduction of pollution or global warming by purchase of green variant.

Source: Author's own research.

Table 6 Multiple Regression Analysis Table for Showing Relationship Between Non-Buyer's

Expectation and Non-Buyer's Product Preference Of Tooth Paste

\begin{tabular}{|c|c|c|c|c|}
\hline Model Number & $\mathrm{R}$ Value & R Square & $\begin{array}{c}\text { R Square } \\
\text { after } \\
\text { adjustment }\end{array}$ & Standard error of the Estimate \\
\hline 1 & .675 & .456 & .445 & .60437 \\
\hline
\end{tabular}

Table 6A Anova Table for Multiple Regression

\begin{tabular}{|l|l|r|r|r|r|r|}
\hline $\begin{array}{l}\text { Model } \\
\text { Number }\end{array}$ & \multicolumn{1}{|c|}{$\begin{array}{c}\text { Value of Sum of } \\
\text { Squares }\end{array}$} & DOF & $\begin{array}{c}\text { Value of Mean } \\
\text { Square }\end{array}$ & $\begin{array}{c}\text { F } \\
\text { value }\end{array}$ & $\begin{array}{c}\text { Sig } \\
\text { value. }\end{array}$ \\
\hline \multirow{3}{*}{1} & $\begin{array}{l}\text { Regression } \\
\text { value }\end{array}$ & 119.934 & 8 & 14.992 & 41.044 & 0.000 \\
\cline { 2 - 7 } & Residual value & 143.183 & 392 & 0.365 & & \\
\cline { 2 - 7 } & Total & 263.117 & 400 & & & \\
\hline
\end{tabular}

Table 6B Multiple Regression Analysis Table for Showing Relationship Between Non-Buyer's Expectation and Non-Buyers' Product Prference of Tooth Paste

\begin{tabular}{|c|c|c|c|c|c|c|}
\hline \multirow{2}{*}{$\begin{array}{l}\text { Model } \\
\text { Number }\end{array}$} & & \multicolumn{2}{|c|}{$\begin{array}{c}\text { Unstandardized } \\
\text { Coefficients }\end{array}$} & \multirow{2}{*}{$\begin{array}{c}\begin{array}{r}\text { Standardized } \\
\text { Coefficients }\end{array} \\
\text { Beta }\end{array}$} & \multirow{2}{*}{$\begin{array}{c}\mathrm{T} \\
\text { value }\end{array}$} & \multirow[b]{2}{*}{ Sig.value } \\
\hline & & B & Std. Error & & & \\
\hline \multirow[t]{9}{*}{1} & $\begin{array}{l}\text { (Constant } \\
\text { value) }\end{array}$ & 1.441 & 0.223 & & 6.476 & 0.000 \\
\hline & A 1 & 0.644 & 0.043 & 0.644 & 14.846 & 0.000 \\
\hline & A 2 & -0.063 & 0.048 & -0.074 & -1.310 & 0.191 \\
\hline & A 3 & 0.099 & 0.037 & 0.108 & 2.659 & 0.008 \\
\hline & A 4 & 0.033 & 0.041 & 0.047 & 0.808 & 0.419 \\
\hline & A 5 & 0.037 & 0.030 & 0.047 & 1.202 & 0.230 \\
\hline & A 6 & -0.004 & 0.032 & -0.005 & -0.120 & 0.904 \\
\hline & A 7 & -0.018 & 0.041 & -0.024 & -0.445 & 0.657 \\
\hline & A 8 & -0.079 & 0.040 & -0.110 & -1.988 & 0.047 \\
\hline
\end{tabular}

Source: Author's own research.

As shown in Table 6A, the significance value of ANOVA results was $<0.05$. The regression co-efficient was significant with a value not at the zero level. Nonbuyers' product expectations of A1, A3, and A8 showed a significant relationship with nonbuyers' buying preference of toothpaste with a significance value of $<0.05$. The role of nonbuyers' expectations for the aforementioned three products in the buying preference for toothpaste was $45.6 \%\left(\mathrm{R}^{2}=0.46\right)$ as shown in Table 6. This indicates that when a regular brand of toothpaste is introduced as a green variant, then nonbuyers' product expectations will be A1, A3, and A8.

Nonbuyer's product expectations for the toothpaste category were that it should be environmentally friendly, preserve the earth, and reduce water consumption (A1); it should 
have the ability to improve personal health and well-being more efficiently than regular nongreen brands (with chemicals) (A3); and it should provide information regarding the pollution level or the pollution level should be minimised by the purchase of natural/herbal/green variants (A8).

Table 7 Multiple Regression Analysis for Examining the Relationship Between Nonbuyers' Expectation and Nonbuyers' Product Preference Of Bath Soap

\begin{tabular}{|l|c|c|c|c|}
\hline $\begin{array}{l}\text { Model } \\
\text { Number }\end{array}$ & $\begin{array}{c}\mathrm{R} \\
\text { Value }\end{array}$ & $\begin{array}{c}\mathrm{R} \\
\text { Square }\end{array}$ & $\begin{array}{c}\text { R Square after } \\
\text { adjustment }\end{array}$ & $\begin{array}{c}\text { Standard error Error of } \\
\text { the Estimate }\end{array}$ \\
\hline 1 & 0.582 & 0.339 & 0.326 & 0.60129 \\
\hline
\end{tabular}

Table 7A Anova Table for Multiple Regression

\begin{tabular}{|l|l|r|r|r|r|r|}
\hline $\begin{array}{l}\text { Model } \\
\text { Number }\end{array}$ & \multicolumn{1}{c|}{$\begin{array}{c}\text { Sum of } \\
\text { Squares }\end{array}$} & dof & \multicolumn{1}{c|}{$\begin{array}{c}\text { Mean Square } \\
\text { value }\end{array}$} & $\begin{array}{c}\text { F } \\
\text { value }\end{array}$ & Sig.value \\
\hline \multirow{3}{*}{1} & $\begin{array}{l}\text { Regression } \\
\text { value }\end{array}$ & 72.68 & 8 & 9.085 & 25.130 & 0.000 \\
\cline { 2 - 7 } & Residual value & 141.73 & 392 & 0.362 & & \\
\cline { 2 - 7 } & Total & 214.41 & 400 & & & \\
\hline
\end{tabular}

Table 7B Relationship Between Nonbuyers' Expectation and Product Preference of Bath Soap By Mulitiple Regression

\begin{tabular}{|c|c|c|c|c|c|c|}
\hline \multirow{2}{*}{$\begin{array}{l}\text { Model } \\
\text { Number }\end{array}$} & & \multicolumn{2}{|c|}{ Unstandardized Coefficients } & \multirow{2}{*}{$\begin{array}{c}\begin{array}{l}\text { Standardized } \\
\text { Coefficients }\end{array} \\
\text { Beta } \\
\end{array}$} & \multirow{2}{*}{$\begin{array}{c}\mathrm{T} \\
\text { value }\end{array}$} & \multirow[b]{2}{*}{ Sig.value } \\
\hline & & $\mathrm{B}$ & Std. Error & & & \\
\hline \multirow[t]{9}{*}{1} & (Constant value) & 0.952 & 0.221 & & 4.300 & 0.000 \\
\hline & A 1 & 0.259 & 0.043 & 0.287 & 5.997 & 0.000 \\
\hline & A 2 & 0.161 & 0.048 & 0.209 & 3.376 & 0.001 \\
\hline & A 3 & 0.102 & 0.037 & 0.124 & 2.762 & 0.006 \\
\hline & A 4 & 0.099 & 0.041 & 0.155 & 2.407 & 0.017 \\
\hline & A 5 & 0.068 & 0.030 & 0.096 & 2.240 & 0.026 \\
\hline & A 6 & -0.029 & 0.032 & -0.043 & -0.906 & 0.365 \\
\hline & A 7 & 0.102 & 0.041 & 0.148 & 2.527 & 0.012 \\
\hline & A 8 & -0.001 & 0.040 & -0.002 & -0.030 & 0.976 \\
\hline
\end{tabular}

Source: Author's own research

As shown in Table 7A, ANOVA results showed that the significance value was $<0.05$. The regression co-efficient was significant with a value not at the zero level. A1, A2, A3, A4, A5, and A7 had a significance value of $<0.05$. According to the aforementioned product expectations, nonbuyers' purchase intention of bath soap was $33.9 \%\left(\mathrm{R}^{2}=0.339\right)$. These results indicate that when a non-green product used by nonbuyers in the bath soap category is introduced as a green variant, then the nonbuyers' product expectation will be A1, A2, A3, A4, A5, and A7.

The nonbuyers' product expectations for bath soap were as follows: it should be environmentally friendly, preserve the earth, and conserve water (A1); it should provide better and faster results compared with regular non-green brands (A2); it should improve personal health and well-being more effectively than regular non-green brand (with chemicals) (A3); it should have an environmentally friendly packaging that is bio-degradable, and a discount should be offered for the recycling of the package (A4); the price quoted for eco-friendly products may be high and need not offer value for money (A5); and retail stores should display how buying of these brands is beneficial to society and preserves mother earth (A7). 
Table 8 Multiple Regression Analysis Table for Examining the Relationship Between Nonbuyers' Product Expectation and Product Prference Regarding Shampoo

\begin{tabular}{|l|r|r|r|r|}
\hline Model Number & R Value & R Square & R Square after adjustment & Standard Error of the Estimate \\
\hline 1 & 0.614 & 0.377 & 0.364 & 0.58280 \\
\hline
\end{tabular}

Table 8A ANOVA Table for Multiple Regression

\begin{tabular}{|l|l|r|r|r|r|r|}
\hline Model & & Sum of Squares & DOF & Mean Square value & F-Value & Sig.value \\
\hline \multirow{3}{*}{1} & Regression value & 80.490 & 8 & 10.061 & 29.622 & 0.000 \\
\cline { 2 - 8 } & Residual value & 133.146 & 392 & 0.340 & & \\
\cline { 2 - 8 } & Total & 213.636 & 400 & & & \\
\hline
\end{tabular}

Table 8B Relationship Between Non-Buyer's Expectation and Product Buying Preference of Shampoo Using Mulitiple Regression Analysis

\begin{tabular}{|c|c|c|c|c|c|c|}
\hline \multirow{2}{*}{$\begin{array}{l}\text { Model } \\
\text { Number }\end{array}$} & & \multicolumn{2}{|c|}{$\begin{array}{l}\text { Unstandardized } \\
\text { Coefficients }\end{array}$} & \multirow{2}{*}{$\begin{array}{c}\begin{array}{c}\text { Standardized } \\
\text { Coefficients }\end{array} \\
\text { Beta }\end{array}$} & \multirow{2}{*}{$\begin{array}{c}\mathrm{t}- \\
\text { value }\end{array}$} & \multirow[b]{2}{*}{ Sig.value } \\
\hline & & B & Std. Error & & & \\
\hline \multirow[t]{9}{*}{1} & $\begin{array}{l}\text { (Constant } \\
\text { value) }\end{array}$ & 0.999 & 0.215 & & 4.656 & 0.000 \\
\hline & A 1 & 0.125 & 0.042 & 0.139 & 2.991 & 0.003 \\
\hline & A 2 & 0.109 & 0.046 & 0.142 & 2.362 & 0.019 \\
\hline & A 3 & 0.102 & 0.036 & 0.123 & 2.834 & 0.005 \\
\hline & A 4 & 0.126 & 0.040 & 0.200 & 3.181 & 0.002 \\
\hline & A 5 & 0.093 & 0.029 & 0.133 & 3.178 & 0.002 \\
\hline & A 6 & 0.021 & 0.031 & 0.032 & 0.688 & 0.492 \\
\hline & A 7 & 0.128 & 0.039 & 0.186 & 3.266 & 0.001 \\
\hline & A 8 & 0.051 & 0.039 & 0.079 & 1.328 & 0.185 \\
\hline
\end{tabular}

Source: Author's own research.

As shown in Table 8A, ANOVA results had a significance value of $<0.05$. The regression co-efficient was significant. with a value not at the zero level. These results indicate that nonbuyers' expectation of A1, A2, A 3, A4, A5 and A7 have relationship with buying preference of shampoo as level of significance value is below .05 for 6 expectations. The total contribution of the aforementioned six expectations for the buying preference of shampoo was $37.7 \%\left(\mathrm{R}^{2}=0.38\right)$. This result indicates that when regular non-green product in the shampoo category is launching a green variant, then nonbuyers' product attribute expectations will be A1, A2, A3, A4, A5, and A7.

Table 9 Multiple Regression Analysis for Examining The Relationship Between Respondents' Product Expectation and Buying Intention of Face Wash

\begin{tabular}{|l|r|r|r|r|}
\hline Model Number & R Value & R Square & R Square after adjustment & Standard Error of the Estimate \\
\hline 1 & 0.572 & 0.327 & 0.313 & 0.67765 \\
\hline
\end{tabular}

Table 9A ANOVA Table for Multiple Regression

\begin{tabular}{|l|l|r|r|r|r|r|}
\hline Model & & Sum of Squares & DOF & Mean Square & F-value & Sig.value \\
\hline \multirow{3}{*}{1} & Regression value & 87.478 & 8 & 10.935 & 23.812 & 0.000 \\
\cline { 2 - 7 } & Residual value & 180.008 & 392 & 0.459 & & \\
\cline { 2 - 7 } & Total & 267.486 & 400 & & & \\
\hline
\end{tabular}


Table 9B Relationship Between Respondent's Product Expectation and Product Buying Preference Of Face Wash Using Mulitple Regression Analysis

\begin{tabular}{|c|c|c|c|c|c|c|}
\hline \multirow{2}{*}{$\begin{array}{l}\text { Model } \\
\text { Number }\end{array}$} & & \multicolumn{2}{|c|}{$\begin{array}{c}\text { Unstandardized } \\
\text { Coefficients }\end{array}$} & \multirow{2}{*}{$\begin{array}{c}\begin{array}{c}\text { Standardized } \\
\text { Coefficients }\end{array} \\
\text { Beta }\end{array}$} & \multirow{2}{*}{$\begin{array}{c}\mathrm{t}- \\
\text { value }\end{array}$} & \multirow[b]{2}{*}{ Sig.value } \\
\hline & & $\mathrm{B}$ & Std. Error & & & \\
\hline \multirow[t]{9}{*}{1} & $\begin{array}{l}\text { (Constant } \\
\text { value) }\end{array}$ & 0.622 & 0.250 & & 2.492 & 0.013 \\
\hline & A 1 & 0.142 & 0.049 & 0.141 & 2.924 & 0.004 \\
\hline & A 2 & 0.099 & 0.054 & 0.115 & 1.845 & 0.066 \\
\hline & A 3 & 0.100 & 0.042 & 0.108 & 2.397 & 0.017 \\
\hline & A 4 & 0.175 & 0.046 & 0.247 & 3.794 & 0.000 \\
\hline & A 5 & 0.131 & 0.034 & 0.166 & 3.837 & 0.000 \\
\hline & A 6 & 0.063 & 0.036 & 0.084 & 1.758 & 0.079 \\
\hline & A 7 & 0.104 & 0.046 & 0.134 & 2.269 & 0.024 \\
\hline & A 8 & 0.024 & 0.045 & 0.033 & 0.536 & 0.592 \\
\hline
\end{tabular}

Source: Author's own research.

As shown in Table 9A, ANOVA results showed that the significance value was $<0.05$. It could be interpreted that respondent's expectation of A1, A 3, A4, A5 and A7 have relationship for buying preference of face wash as significance value is below .05 for these 5 expectations. The overall contribution of the aforementioned five product expectations for the buying preference of face wash was $32.7 \%\left(\mathrm{R}^{2}=0.33\right)$. These results indicated that when a regular nongreen product or brand used in the face wash category is launched as a green variant, then nonbuyers' product expectations for positive buying intention will be A1, A3, A4, A5 and A7.

Thus, the hypothesis of this study is rejected because a significant relationship was observed between nonbuyers' product expectations and buying preferences of environmentally friendly variants when introduced by regular well-known brands used by the nonbuyers in all the four product categories studied.

\section{CONCLUSION}

The marketing strategy of introducing a green variant as a line extension strategy by mainstream or regular marketers in the personal care product category, such as Procter and Gamble, Unilever, and Colgate, will be well-received by nonbuyers who are presently consuming their regular non-green brand variants because we observed a positive buying intention for green variants in all the four product categories studies. Nonbuyers' expectations that were common for all the four personal care product categories were as follows: the product should be environmentally friendly, save the mother earth, and reduce water consumption (A1) and it should improve personal health and well-being more effectively than regular brands (with chemicals) (A3). The eco-friendliness of a product and its ability to improve personal health and well-being more effectively than non-green products are crucial product features or attributes that should be present in green variants when introduced. The tooth paste product category had the highest buying intention. The product expectations for the tooth paste category were as follows: it should be eco-friendly, preserve the earth, and conserve water (A1); it should yield instant results when compared with regular non-green brand (A2); it should improve personal health and well-being more effectively than regular brand (with chemicals) (A3); the packaging of the product should be environmentally friendly and biodegradable, and an incentive should be offered for recycling of packaging (A4); the price fixed for environmentally friendly products may be high and need not offer value for the money paid (A5); and the retail store should display how the buying of these brands would be beneficial to society and preserve the earth (A7). Nonbuyers' product expectations for face wash were A1, A3, A4, A5, and A7. 


\section{Managerial Implications}

The results of this study indicated that the eco-friendly variety introduced by mainstream manufacturers must be environmentally friendly, preserve the earth, save water, and improve personal health and well-being more effectively than regular non-green brands. These findings answer the following question raised by Horne (2009): What gets customers interested in natural products? These study findings are in agreement with those reported by Smith (2002) that consumers demand chemical-free products that are biodegradable and promote personal health and environmental well-being. In terms of product expectations, the findings of this study are similar to those reported by Johri and Sahasakmontri (1998) and Ottman (1998). The majority of consumers' product expectations were that the green or environmentally friendly variant must be eco-friendly, save the earth, and conserve water. When we considered the price of the product, the results of this study slightly differ with the findings reported by Peart (2010) that consumers would not pay for a product based on its green product attributes only, and it should have some value additions. This study showed that for the product categories of bath soap, shampoo, and face wash, consumers had additional expectations along with green attributes, but they were willing to pay higher prices and did not expect value for money. However, in the toothpaste category, they expected value for money along with green attributes.

Jain and Kaur (2004 and 2006) and Formichelli (2007) have reported there is a market opportunity for green products because green consumerism is still a limited phenomenon and green sentiments are picking up. Godelnik (2012) indicated that marketing strategies are essential to overcome obstacles and exploit green opportunities. Aich (2006) found that marketers in organic products faced problems in bringing organic products and promoting then without projecting their already existing brands that were not organic. This study attempted and found that introducing an eco-friendly variant as a line extension strategy after understanding product expectations in each product category will be purchased by non-buyers, mainstream players and well-known non -green brands can use this market opportunity. The findings of this study differ from those reported by Kuhn (2005) who reported that the consumption of environmentally friendly products should generate an extra benefit in the form of subsidiaries, and a private incentive is needed to engage in green consumerism as the nonbuyers of natural personal care products of this study were willing to pay higher prices for green products that provide green attributes along with added value in the four product categories except for the tooth paste product category. According to the theory of planned behaviour (Ajzen, 1991), there are three components that are conceptually independent determinants of buying intentions: attitude, which refers to a human being have a favourable or unfavourable assessment of behaviour, subjective norm, which refers to perceived social pressure, and degree of perceived behaviour control, which is the ease or difficulty of performing considering past experiences and anticipated impediments and hurdles or obstacles.

Attitude is based on beliefs and perception. The buying intention for eco-friendly variants by nonbuyers depends on beliefs and perception that will result in a positive attitude towards buying behaviour. A positive attitude towards green variants introduced by regular brand manufacturers can be developed based on how the variant meets product expectations.

The paper further summarises the findings of previous studies on consumers who did not buy existing green products in the market. Brand-loyal customers of regular not green products showed willingness to buy green variants if launched by the mainstream manufacturers as a line extension strategy. For successful implementation of the line extension strategy, understanding consumer expectations regarding each product category can help increase the sales of green variants by mainstream manufacturers. The general product expectation that is common for all product categories is that the green variant must be environmentally friendly, preserve the earth, conserve the water, and promote personal health care and well-being more effectively than 
regular brands. Durmaz and Zengin (2011) reported that green sellers' identification of the appropriate target market segment and development of a marketing mix are important for growth, sustainability, and profit. This approach of the firm enables access to potential markets with a competitive advantage. Furthermore, the findings of this study provide insights into nonbuyers expectations in some areas of product, packaging, price, and promotion, aiding marketers to modify the marketing mix to utilise new marketing opportunities and augment the consumption of natural products in an important emerging market; that is India. Bhatia et al (2013) found that the market should use opportunities in design and manufacture of green products to create a demand for green products by adopting suitable marketing strategies because the percentage of buyers purchasing green products is lower. In addition, this study has thrown light on areas of promotional strategies in product categories studied, such as retail store display, information on packaging, and usage of brand ambassadors. Based on the findings of previous studies in this research area, this study used a marketing strategy of introducing green variants as a line extension strategy by mainstream and well-known brand marketers in the personal care product category and found a positive buying intention among consumers. Our findings provide information regarding expectations from this green variant in terms of the product, price and promotion that will aid in formulating or refining the marketing mix, enabling successful sales of these products, augmenting the overall consumption of natural products manufactured and marketed in an eco-friendly way, and facilitating green marketing that will enable going green in consumption.

This study was conducted in India, an important emerging market. The generalisation of the findings of this study to all geographic locations is limited because socio-cultural factors influencing consumer expectations in product categories studied may vary across locations. Economic factors will also have an effect on study findings. However, the findings of this study can be used as the basic knowledge that can be enhanced by further research in various geographical locations globally for enhancing green consumption. The variables identified as nonbuyers' expectations in terms of the product, price, and promotion can be used as the basis for further research globally in responsible consumption and sustainability. The conclusion and finding of this study may also be used as the basis for further research in the personal care product category and other product categories in other sectors of the industry, such as power, automobile, and public transportation, for going green in consumption globally and in India. This research work contributes to marketing, business and environment domains by providing a marketing perspective for moderating environmental pollution and climate change effects, preventing the effects of pandemics such as the coronavirus, and enhancing the green consumption, thus improving personal health and well-being as an imperative area affecting the world. The findings of this research on green marketing, sustainable development and environment can be used by researchers, academicians, and marketing practitioners globally.

\section{REFERENCES}

[1] Aich Vasudha Chapter 14 Green \& Black's Green Marketing (ICFAI) (2006) First Edition (Page 231).

[2] Icek Ajzen 1991, The Theory of Planned Behaviour (1991), Organizational Behaviour and Human Decision process Vol-50, PP-179-211

[3] Andrea Prothero (1990), Green Consumerism and the Societal Marketing Concept: Marketing Strategies for the 1990's, Journal of Marketing Management, Vol-6, Issue-2, pp 87-103

[4] Artee Agarwal and Nargundar(2016) Proposing frame work for dynamics of green purchase behaviour in India- An empirical study Journal of Services Research, Volume 16, Number 1 (April - September 2016) 
[5] Bhatia Mayank, and Jain Amit(2013), Green marketing -A Study of consumer preferences and perceptions in INDIA -Electronic Green Journal, Issue 36 .

$\begin{array}{lccc}\text { Census } & \text { India(2011) } & \text { accessed } & \text { at } \\ \text { www.censusindia.gov.in/pca/SearchDetails.aspx?Id=674672(accessed on feb 2013) }\end{array}$

$\mathrm{http}$ //www censusindia gov in/PopulationFinder/District_Master aspx?state code=33(acessed on feb 2013)

[8] Chen, Yu-Shan, The Positive Effect of Green Intellectual Capitol on Competitive Advantages of Firms, Journal of Business Ethics, 2008, Vol. 77 (3), 271-286.

[9] Clare D' Souza, Mehdi Taghian and Rajiv Khosla (2007), Examination of environmental beliefs and its impact on the influence of price, quality and demographic characteristics with respect to green purchase intention, Journal of Targeting, Measurement and Analysis for Marketing, Vol -15 , Iss-2, pp $69-78$.

[10] Darrin Duber-Smith.C(2002), Being green, Global Cosmetic Industry, Vol-170, Issue- 9, Abi/inform Global, pp -46.

[11] Debdatta Gupta, Growth of Green products, Chapter 2, Green Marketing Strategies (2008), Icfai University Press Ltd (Page 14)

[12] Doris De Guzman (2008), Green pull, ICIS Chemical business, Vol-274, Issue-14, Abi/inform Global Page-34

[13] Durmazm, Y. and Zengin, S. (2011), A Theoretical Approach To Concept of Green Marketing, Interdisciplinary Journal Of Contemporary Research In Business, Vol. 3, No. 2, pp. 1808-1814

[14] ElhamRahbar and Nabsiah Abdul Wahid (2011), Investigation of green marketing tools' effect on consumers' purchase behavior, Emerald Group Publishing Limited, Business Strategy Series, Vol-12, issue - 2, pp-73-83.

[15] Godelnik, http://www.triplepundit.com/2012/12/sustainable-consumption-trends/

[16] Hartmann, P. and Iba'ñez, V.A. (2006), Green value added, Marketing Intelligence \& Planning, Vol.-24, Issue - 7, pp 673-80 .

[17] Horne(2009), Limits to Labels: Role of eco-label in the assessment of product sustainability and routes to sustainable consumption, International Journal of consumer studies, Vol-33, Issue-2, pp-175-182 .

[18] http://www.surveysystem.com/sscalc.htm)(accessed on Feb 2013 )

[19] Jacquelyn A.ottman(1998) Green Marketing: Opportunity for Innovation, NTC Business

[20] JohriLalit, M. and Kanokthip Sahasakmontri (1998), Green marketing of cosmetics and toiletries in Thailand, The Journal of Consumer Marketing, Vol 15, Issue 3,pp- 265-281 .

[21] Jonatan Pinkse Anskolk (2009)--International Business and Global climate change, European Academy of Business Society-Routledge

[22] Josephine Pickett-Baker, RitsukoOzaki(2008), Pro-environmental products: MarketingInfluence on consumer purchase decision, Journal of Consumer Marketing, Vol-25 Iss-5, pp 281-293 .

[23] Justin Peart,(2010) Green Marketing: Making Sense Of The Situation Proceedings Of The Academy Of Marketing Studies, Volume 15, Number 1, pp-27-68

[24] Kaman Lee(2008), Opportunities for green marketing: young consumers , Marketing Intelligence \& Planning, Vol-26, Issue No- 6, pp 573-586. 
[25] Katherine Smith, $\mathrm{T}(2010)$, An examination of marketing techniques that influence Millennials'perceptions of whether a product is environmentally friendly, Journal of Strategic Marketing,Vol- 18, Issue- 6, pp- 437-450 .

[26] Ken Peattie and Andrew Crane, Chapter 7 Green Marketing: A Critical Look (ICFAI)(2006) First Edition (Page 139-140).

[27] Lakshmi Viswanathan, George Varghese(2018)Greening of business: A step towards sustainability, Journal of Public Affairs, 10.1002/pa.1853, 18, 3, (2018)

[28] Lamb, Hair, Sharma, McDaniel(2012), Marketing-South Asian perspective, Cengage Learning.

[29] Laroche, M., Bergeron, J. and Barbaro-Forleo, G. (2001), Targeting consumers who are willing to pay more for environmentally friendly products, Journal of Consumer Marketing, Vol. 18, Issue No. 6, pp-503-520.

[30] Leila HamzaouiEssoussi and Jonathan Linton, D.(2010), New or recycled products: how much are consumers willing to pay? „Journal of Consumer Marketing, Vol-27, Issue-5, pp-458-468.

[31] Linda Formichelli(2007), Organics Buyers: Going for the Greens ,Target Marketing, Vol-30, Issue 5, pp- 62

[32] Majhi, R. Behavior and perception of younger generation towards green products. J Public Affairs. 2020;e2288. https://doi.org/10.1002/pa.2288

[33] Maslow, A.(1967), Metamotivation, The Humanist, May-June, page 82-84

[34] Nancy Jeffries(2007), Green Convergence ,Global Cosmetic Industry,Vol- 175,Issue- 6, Abi/Inform Global pp- 44

[35] Michael Kuhn(2005), Greening Of Markets Edward Elgar Publishing 2005.

[36] Michael -Lee Johnstone And Stephanie Hooper (2016) Social Influence And Green Consumption Behaviour: A Need For Greater Government Involvement Journal Of Marketing Management, Vol 32,Issue 9-10,Pg

[37] NareshK.Malhotra, SatyabhushanDash(2011),Marketing Research: An Applied orientation, Sixth Edition, Pearson Education Inc

[38] NationalGeographic, Greendexhttp://images.nationalgeographic.com/wpf/mediacontent/file/GS_NGS_2012GreendexHighlights_10July-cb1341934186.pdf

[39] Newman and Karen(2006) A Sustaining Natural Growth, Global Cosmetic Industry, Vol- 174, Issue 4,pp- 32 .

[40] NisreenBahnan, MayureshKelkar, Nicole Curry, Linda Jane Coleman (2011), Walking The Walk: How The Theory Of Reasoned Action Explains Adult And Student Intentions to go Green, Journal of Applied Business Research, Vol-27, Number 3, pp-107

[41] NOAA National Climatic Data Center, State of the Climate: Global Analysis for Annual 2011, accessed at http://www.ncdc.noaa.gov/sotc/global/2011/13(accessed on MAY 5, 2018).

[42] Philip kotler, Kevin lane keller, Abraham Koshy and MithileshwarJha(2009),Marketing Management 13th Edition, South Asian Perspective, Pearson Prentice hall Education Inc,New Delhi

[43] Polonsky M. J. (1994), An Introduction To Green Marketing, Electronic GreenJournal UCLA Library, UC, Vol- 1, Issue-2, pp 1

[44] Sanjay K. Jain * \& Gurmeet Kaur, Green Marketing : An Indian Perspective Decision, JulyDecember 2004 Vol. 31, No. 2, Pg 168

[45] Sanjay K. Jain and Gurmeet Kaur, Chapter 6 Green Marketing: An Attitudinal and Behaviour Analysis of Indian consumers . GREEN MARKETING (ICFAI)(2006) First Edition Page.116 
[46] SenthilNathan C and Malarmathi K, Chapter 5 A study on Green Marketing Adaption for Select Natural Products 2013, BSMED, Bharathiar University.

[47] ShrumMcCarty, L. J., JohnLowrey, A. and Tina.M(1995), Buyer characteristics of the green consumer and their implications for advertising strategy, Journal of Advertising,Vol- 24, Issue2; ProQuest pp- 71

[48] Srinivasa Rao(2014), Green Marketing and Its Impact on Sustainable Development International Journal of Innovative Technology \& Adaptive Management (IJITAM) Volume-1, Issue-5, pp-39

[49] Suresh.K(2006), Green Marketing Concepts and Cases First Edition, ICFAI University Press

[50] Teisl, M.F. and Roe, B. (2005), Evaluating the factors that impact the effectiveness ofecolabeling programmes , Environment, Information and Consumer Behaviour, Cheltenham: Elgar, pp 65-90.

[51] Uberoi.NK(2003) Environmental Management, second edition, excel books, New Delhi()

[52] Uma Sekaran(2003), Research Methodology for business: A Skill building approach(4th Edition), John wiley\& sons Inc

[53] Valor, C. (2008), Can consumers buy responsibly?Analysis and solutions for market failures, Journal of Consumer Policy, Vol-31, Issue-3, pp-315-326 .

[54] Vasudha, A. (2006), Green \& Black's Green Marketing (ICFAI)(2006), Chapter 14, First Edition (pp 231).

[55] Zimmer, M., Stafford, T., and Stafford, M. (1994), Green issues: Dimensions of environmental concern, Journal of Business Research, 30 May 1994, pp- 63-74

[56] Zuhairah Hasana and Noor Azman Alib (2015), The impact of green marketing strategy on the firm's performance in Malaysia Elsevier Procedia - Social and Behavioral Sciences 172 (2015), pp- $463-470$ 